\title{
Состав, структура, полупроводниковые свойства химически осажденных пленок SnSe
}

\author{
(С) Л.Н. Маскаева ${ }^{1,2}$, Е.А. Федорова ${ }^{1}$, В.Ф. Марков ${ }^{1,2}$, М.В. Кузнецов ${ }^{3}$, О.А. Липина ${ }^{3}$ \\ ${ }^{1}$ Уральский федеральный университет им. первого Президента России Б.Н. Ельцина, \\ 620002 Екатеринбург, Россия \\ ${ }^{2}$ Уральский институт ГПС МЧС России, \\ 620062 Екатеринбург, Россия \\ ${ }^{3}$ Институт химии твердого тела Уральского отделения Российской академии наук, \\ 620990 Екатеринбург, Россия \\ E-mail: mln@ural.ru
}

Поступила в Редакцию 27 декабря 2018 г.

В окончательной редакции 14 января 2019 г.

Принята к публикации 14 января 2019 г.

Гидрохимическим осаждением из трилонатной реакционной смеси получены высокоадгезионные слои моноселенида олова $(\mathrm{SnSe})$ толщиной до $(200 \pm 10)$ нм. Рентгеновской дифракцией установлено, что синтезированные пленки кристаллизуются в орторомбической сингонии (пр. гр. Рnта). Присутствие в поверхностных слоях пленок значительного количества кислорода объясняется частичным окислением образцов с формированием фазы $\mathrm{SnO}_{2}$. Результаты ионного травления на глубину до 18 нм показали резкое снижение содержания кислорода по толщине и фактическое соответствие их элементному составу $\mathrm{SnSe}$. Установленная по результатам оптических исследований ширина запрещенной зоны для прямых переходов составила 1.69 эВ. Синтезированные слои $\mathrm{SnSe}$ имеют характерный для этого материала дырочный тип проводимости.

DOI: 10.21883/FTP.2019.06.47744.9058

\section{1. Введение}

Моноселенид олова $\mathrm{SnSe}$ является широко востребованным полупроводниковым соединением, уникальные свойства которого, в частности высокая химическая стабильность, высокий коэффициент поглощения $\left(\sim 10^{5} \mathrm{~cm}^{-1}\right)$, а также значение ширины запрещенной зоны $1.0-1.5$ эВ и устойчивый $p$-тип проводимости с развитием фотовольтаики привлекают все большее внимание [1-3]. Это бинарное соединение может быть использовано не только в качестве прекурсорного слоя при создании солнечных элементов на основе кестеритной структуры $\mathrm{Cu}_{2} \mathrm{ZnSnSe}$, ожидается, что селенид олова в ближайшем будущем может сыграть важную роль в замене четырехкомпонентных по составу кестеритов. Как отмечается в [2,4,5], это произойдет благодаря значительному содержанию олова в земной коре, его сравнительной экологической безопасности и, что немаловажно, высокому (до 32\%) теоретическому коэффициенту эффективности превращения солнечного излучения в электрическую энергию.

Другим потенциально важным применением тонкопленочного селенида олова благодаря его сверхнизкой теплопроводности $\left(<3 \mathrm{BT} \cdot \mathrm{M}^{-1} \cdot \mathrm{K}^{-1}\right.$ при $\left.300 \mathrm{~K}\right)$ и высокой подвижности носителей заряда $\left(10^{4} \mathrm{~cm}^{2} \cdot \mathrm{B}^{-1} \cdot \mathrm{c}^{-1}\right)$ является прямое твердотельное преобразования энергии.

Отражением неослабевающего интереса к исследованию моноселенида олова в самых разнообразных аспектах служит обилие публикаций за последние пять лет. Высокая чувствительность этого соединения к механи- ческим нагрузкам - низкое напряжение, 1.6 ГПа, вызывающее геометрический фазовый переход, осевые деформации, < 0.5 ГПа, приводящие к изменению прямой запрещенной зоны на непрямую, - дают основание полагать, что SnSe может стать востребованным материалом для наномеханики и оптоэлектроники [6]. Кроме того, $\mathrm{SnSe}$ - перспективный материал для изготовления транзисторов с высокой скоростью переключения с помощью электрического, термического, механического или оптического методов. К тому же селенид олова является сегнетоэластичным материалом [7], т.е. обладает спонтанной упругостью, возникающей при понижении температуры, а в определенном интервале температур в нем наблюдается возникновение спонтанной поляризации даже в отсутствие электрического поля (сегнетоэлектрический фазовый переход) [8]. Еще одно потенциальное применение этого материала намечается в устройствах „памяти“ при температурах ниже комнатных [9].

Физические характеристики тонкопленочного селенида олова (II), т. е. величина оптической запрещенной зоны, направление и степень ориентации преимущественного роста кристаллитов, элементный состав, в значительной степени зависят от метода получения. Исследовательские работы последнего десятилетия по синтезу монооксида олова проводили в основном физическими методами, включающими термическое испарение [10,11], молекулярно-лучевое осаждение (CMBD) [3,12], метод реактивного испарения [13]. Однако разработка химического метода осаждения пленок $\mathrm{SnSe}$, предполагающего простоту ведения процесса, исключающего 
использование дорогостоящего оборудования, высоких температур и давлений, а также обеспечивающего ведение синтеза в относительно „мягких“ условиях из коллоидно-химических сред, открывает значительную перспективу получения наноструктурированных слоев селенида олова [14-18].

В настоящем сообщении представлены результаты химического осаждения тонких пленок $\mathrm{SnSe}$, исследования их элементного и фазового состава, кристаллической структуры и некоторых полупроводниковых свойств.

\section{2. Методика эксперимента}

Пленки селенида олова (II) на ситалловой или матированной стеклянной подложках получали путем химического осаждения из водного раствора хлорида олова $\mathrm{SnCl}_{2}$ и селеносульфата натрия $\mathrm{Na}_{2} \mathrm{SeSO}_{3}$ в присутствии динатриевой соли этилендиаминтетрауксусной кислоты $\mathrm{C}_{10} \mathrm{H}_{14} \mathrm{~N}_{2} \mathrm{Na}_{2} \mathrm{O}_{8}$ (Трилон Б). Осаждение проводили при температуре $343 \mathrm{~K}$ в течение 120 мин.

Толщины синтезированных пленок $\mathrm{SnSe}$ оценивали с помощью интерференционного микроскопа МИИ-4М (микроинтерферометра Линника).

Изучение структурно-морфологических характеристик и элементного состава пленок проводили методом растровой электронной микроскопии с использованием микроскопа MIRA3LMV при ускоряющем напряжении электронного пучка $10 \mathrm{\kappa B}$, а также растрового электронного микроскопа JEOL JSM-5900 LV с приставкой для энергодисперсионного (EDX) анализа (EDS Inca Energy 250).

Кристаллическую структуру и фазовый состав пленок исследовали при комнатной температуре на рентгеновском дифрактометре ShimadzuXRD-7000 в $\mathrm{Cu} K_{\alpha 1,2}$-излучении в интервале углов $2 \theta=15-75^{\circ}$ с шагом $\Delta(2 \theta)=0.03^{\circ}$ в $1 \mathrm{c}$ и экспозицией $7 \mathrm{c}$ в каждой точке. Интерпретацию рентгенограмм осуществляли с использованием программы WinPLOTR, входящей в состав программного обеспечения Fullprof, а также PowderCell 2.3, Match и картотеки базы данных ICCD (International Centre for Diffraction Data).

Оценку состава, степени окисления и валентное состояние элементов в полученных пленках изучали методом рентгеновской фотоэлектронной (РФЭ) спектроскопии поверхности [19]. Для исследования профилей распределения примесей по глубине осуществляли ионное травление поверхностных слоев аргоновым пучком.

Элементный анализ приповерхностных слоев тонких пленок SnSe был выполнен на сверхвысоковакуумном исследовательском комплексе (давление остаточных газов до $10^{-6}$ Па), собранном на базе электронного спектрометра ESCALAB MK II производства фирмы „VG Scientific Ltd“ (Великобритания) с точностью определения элементов 0.3-1.0 ат\%. Источником немонохроматического рентгеновского излучения выступал магниевый катод $\operatorname{Mg} K_{\alpha}(1253.6$ эВ). Для интерпретации типа химических связей элементов по сдвигу полос в РФЭ-спектрах в качестве калибровочных использовали линии углерода $\mathrm{C} 1 s$ с энергией связи 284.5 эВ и олова $\operatorname{Sn} 3 d$ с энергией связи 485.43 эВ. Управление экспериментом, сбор и первичную обработку данных осуществляли с использованием программ, созданных в пакете LabView. Обработку РФЭ-спектров проводили с использованием программы XPSPEAK.

Для установления оптической ширины запрещенной зоны осажденных пленок регистрацию спектров поглощения и диффузного отражения бинарных слоев $\mathrm{SnSe}$, осажденных на матированное стекло, выполняли на спектрофотометре UV-3600 Shimadzu (Япония), оснащенном приставкой ISR-3100 с интегрирующей сферой. Съемку спектров поглощения проводили относительно воздуха в диапазоне длин 220-2600 нм с шагом 2 нм. Для определения края поглощения использовали соотношение Бардина [20], в котором коэффициент поглощения материала $\alpha$ связан с энергией падающих на него фотонов $h v$ уравнением

$$
(\alpha h v)^{n}=A\left(h v-E_{g}\right) .
$$

Здесь $\alpha-$ коэффициент поглощения, $A-$ коэффициент, зависящий от пропускающей способности пленки и ее толщины $d, E_{g}$ - оптическая ширина запрещенной зоны, $n$ - коэффициент, характеризующий тип оптических переходов, для прямых оптических переходов $n=2$.

Оптическую ширину запрещенной зоны осажденных пленок определяли графически путем построения зависимости значений $(\alpha h v)^{n}$ от энергии падающих фотонов $h v$ с последующей проекцией касательной на ось абсцисс.

Тип проводимости полупроводниковых слоев устанавливали методом термоэдс.

\section{3. Результаты и обсуждение}

Путем варьирования концентраций компонентов реакционной смеси и условий проведения химического осаждения были оптимизированы параметры процесса. Затем на ситалловых и матированных стеклянных подложках проведено осаждение полупроводниковых высокоадгезионных слоев селенида олова (II) толщиной до $(190 \pm 10)$ нм.

Важным этапом работы было выяснение причины присутствия большого количества кислорода: входит ли он в состав кислородсодержащих фаз олова или его наличие обусловлено оксидной природой ситалловой подложки. С этой целью была применена рентгеновская фотоэлектронная спектроскопия поверхности и приповерхностных слоев соединения.

Обзорные РФЭ-спектры, полученные до и после ионного травления пленок ионным пучком аргона в течение 3 мин (на глубину $18 \mathrm{Hм}$ ), показаны на рис. 1. В спектре $\mathrm{SnSe}$, характеризующем состояние поверхно- 


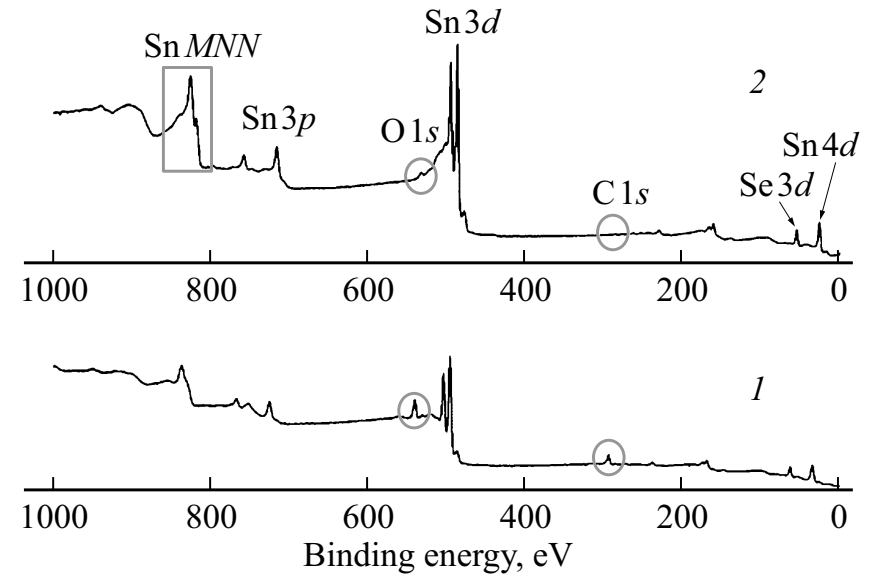

Рис. 1. Обзорные РФЭ-спектры поверхности химически осажденной из трилонатной реакционной смеси пленки $\mathrm{SnSe}$ до (1) и после (2) ионного травления аргоновым пучком в течение 3 мин.

сти анализируемой пленки, наблюдаются фотоэлектронные и оже-линии элементов $\mathrm{Sn}, \mathrm{Se}, \mathrm{O}$ и С. Трехминутное травление аргоновым пучком поверхностного слоя приводит к значительному снижению интенсивности линии, соответствующей кислороду $\mathrm{O} 1 s$. РФЭ-спектр показал присутствие углерода лишь на поверхности исследуемого полупроводникового соединения (рис. 1).

Наличие кислорода в приповерхностных слоях осажденной пленки может быть объяснено либо органическими загрязнениями и кислородсодержащими примесями гидроксида олова [21], либо гиббсовской адсорбцией кислорода на межфазной границе раздела твердое-газ или твердое-жидкость, обусловленной избыточной поверхностной энергией слоя SnSe [22].

Для определения химического состояния элементов в поверхностных слоях селенида олова (II) более детально были изучены РФЭ-спектры внутренних электронных уровней $\mathrm{Sn}, \mathrm{Se}, \mathrm{O}$ и С. Для учета зарядки образца использовали линию $\mathrm{C} 1 s$ от полифенилового эфира (284.5 эВ). РФЭ-спектр $\mathrm{Sn} 3 d$-состояния олова пленки SnSe (рис. 2,a) свидетельствует о том, что на поверхности исследуемого образца присутствует оксид олова $\mathrm{SnO}_{x}$. Стоит отметить, что РФЭ-спектроскопия неоднозначно трактует энергию связи остовных уровней $\operatorname{Sn} 3 d$ и $\mathrm{O} 1 s \mathrm{~B}^{\mathrm{SnO}} \mathrm{Z}_{2}$ и $\mathrm{SnO}$. Авторы публикаций [23-27] полагают, что значение энергии уровня $\operatorname{Sn} 3 d$ монооксида металла может быть меньше, совпадать или превышать значение энергии $\operatorname{Sn} 3 d$-уровня диоксида $\left(E_{b}=486.58-487.1\right.$ эВ). Однако ввиду неустойчивости соединения $\mathrm{SnO}$ можно предположить, что на поверхности пленки $\mathrm{SnSe}$ произошло окисление $\mathrm{Sn}^{2+}$ до $\mathrm{Sn}^{4+}$ и формирование фазы диоксида $\mathrm{SnO}_{2}$.

Помимо окисленной формы олова на поверхности была установлена также характерная для связи в соединении SnSe составляющая $E_{b}=485.43$ эВ [28]. После ионного травления аргоновым пучком спектр $\operatorname{Sn} 3 d$-линии содержит в себе лишь одну эту компоненту, свойственную только химической связи $\mathrm{Sn}-\mathrm{Se}$.

Анализ спектров $3 d$-уровней селена до и после травления образца пленки в течение 3 мин пучком $\mathrm{Ar}^{+}$(рис. 2,b) показал, что халькоген находится только в одной химической форме $\mathrm{SnSe}\left(E_{b}=\right.$ $=53.4-53.55$ эВ) [28-32].

РФЭ-спектры кислорода (рис. 3,a) свидетельствуют о том, что как на поверхности тонкопленочного слоя, так и на глубине (18 нм) О1s-линии содержат две компоненты с энергиями связи 530.55-530.69 и 532.25-532.76 эВ.

Первую составляющую можно отнести к кислороду, связанному с оловом, возможно, в виде $\mathrm{SnO}_{2}$, тогда как вторую - к адсорбированным видам кислорода в составе групп $\mathrm{OH}^{-}$или воды. К аналогичным выводам пришли авторы нескольких работ, посвященных изучению состояния поверхностных слоев оксидов и селенидов олова $[23,24,26,27,32,33]$.

Что касается углерода, его присутствие, согласно РФЭ-спектрам (рис. $3, b$ ), зарегистрировано лишь на поверхности анализируемой пленки $\mathrm{SnSe}$, причем компоненты C1 $s$-линии с максимумами на энергии связи 284.5 и 285.82 эВ соответствуют углеводородным загрязнениям $[27,34]$.

Содержание основных элементов по результатам РФЭ-анализа в поверхностном слое свежеосажденной пленки $\mathrm{SnSe}$, а также на глубине 18 нм, оцененное по величине площади под наиболее интенсивными линиями для каждого элемента, приведено в таблице. Примесь углерода в общем элементном составе пленок не учитывали.

Из таблицы видно, что удаление от поверхности на глубину 18 нм приводит к снижению относительной концентрации кислорода с $\sim 42$ до $\sim 12.8$ ат\%. Рассмотренные выше РФЭ-спектры О1s-линий позволяют заключить, что источником значительного количества кислорода является окисление $\mathrm{SnSe}$ до $\mathrm{SnO}_{2}$, что характерно для этого металла в воздушной среде [35]. Превышение содержания олова по отношению к халькогену связано с включением его в состав оксидных или гидроксидных соединений.

По данным рентгеновской дифракции установлена кристаллическая структура синтезированной пленки. На полученной рентгенограмме присутствуют дифракционные отражения (111), (400) и (311), характерные для орторомбического (пр. гр. Рпта) селенида олова (рис. 4,2) [12,36,37], причем наблюдается преимущественная ориентация кристаллитов в плоскости $\{111\}$.

Содержание основных элементов (в ат\%) в поверхностных слоях свежеосажденной пленки селенида олова (II)

\begin{tabular}{l|c|c|c}
\hline \multicolumn{1}{c|}{ Элементы } & $\mathrm{Sn}$ & $\mathrm{Se}$ & $\mathrm{O}$ \\
\hline Поверхность & 37.14 & 20.47 & 42.39 \\
На глубине 18 нм & 55.61 & 31.58 & 12.81
\end{tabular}



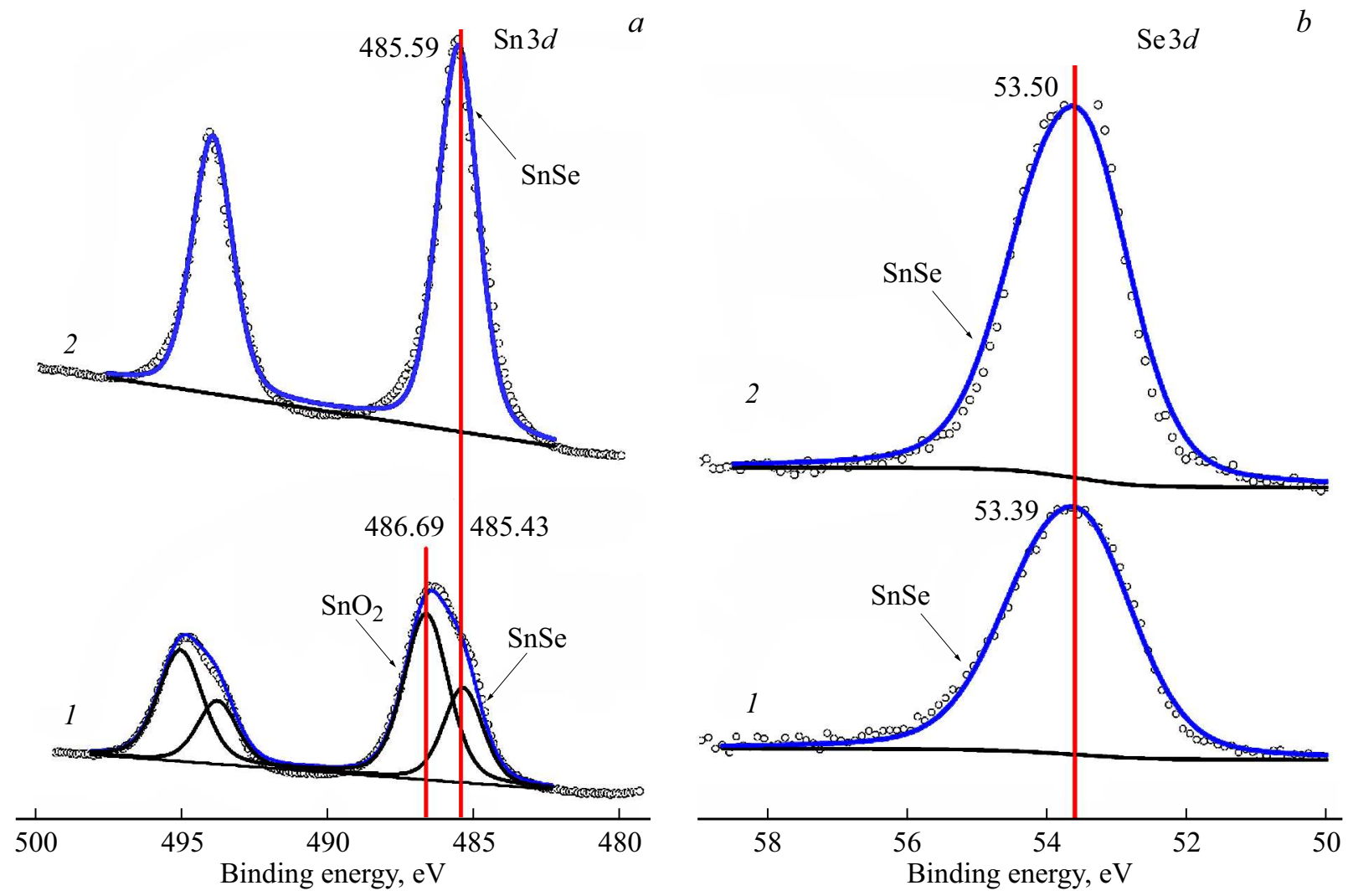

Рис. 2. РФЭ-спектры $\operatorname{Sn} 3 d$-уровней олова $(a)$ и $\mathrm{Se} 3 d$-уровней селена $(b)$ в пленке $\mathrm{SnSe}$ до $(1)$ и после $(2)$ ионного травления. Угол регистрации фотоэлектронов $90^{\circ}$.
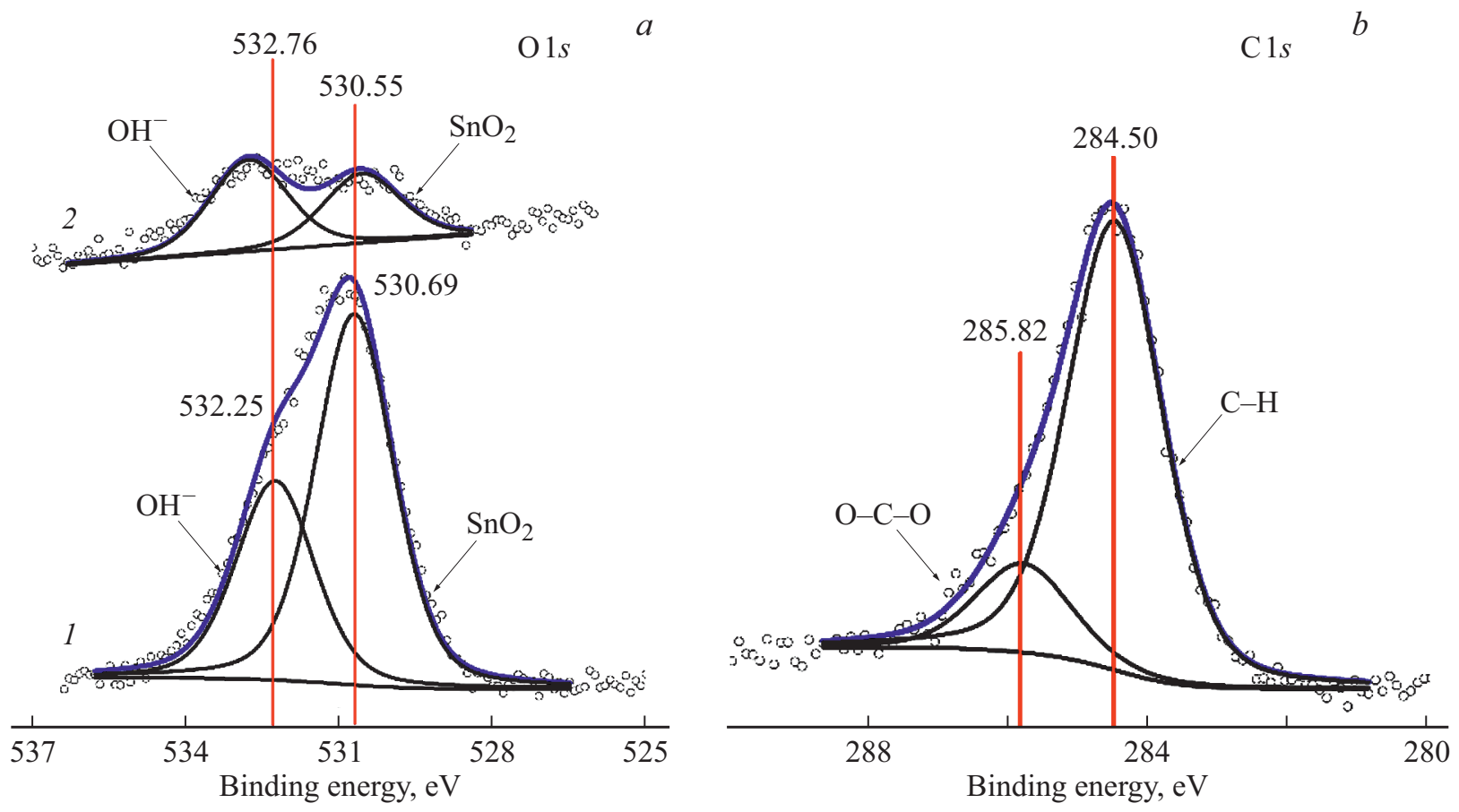

Рис. 3. РФЭ-спектры $\mathrm{O} 1 s$-уровней кислорода $(a)$ и $\mathrm{C} 1 s$-уровней углерода $(b)$ в пленке $\mathrm{SnSe}$ до $(1)$ и после $(2)$ ионного травления. Угол регистрации фотоэлектронов $90^{\circ}$. 


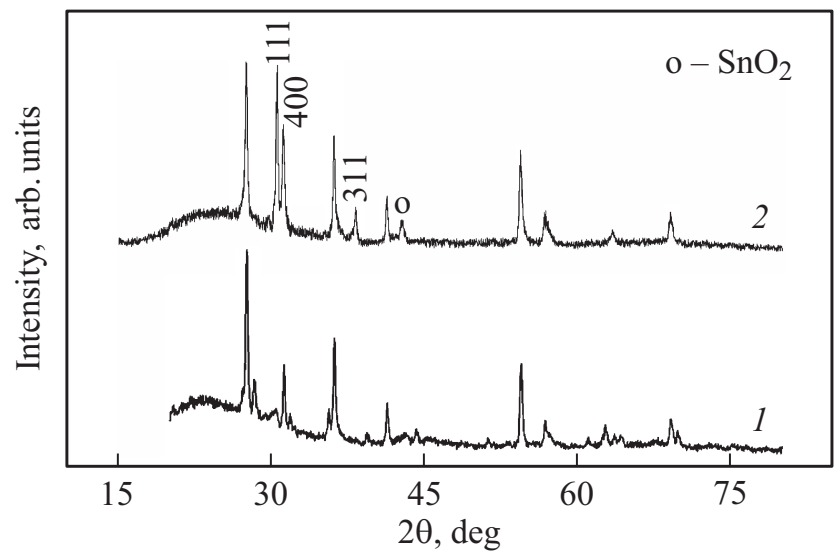

Рис. 4. Рентгенограммы ситалловой подложки (1) и тонкой пленки $\mathrm{SnSe}(2)$.

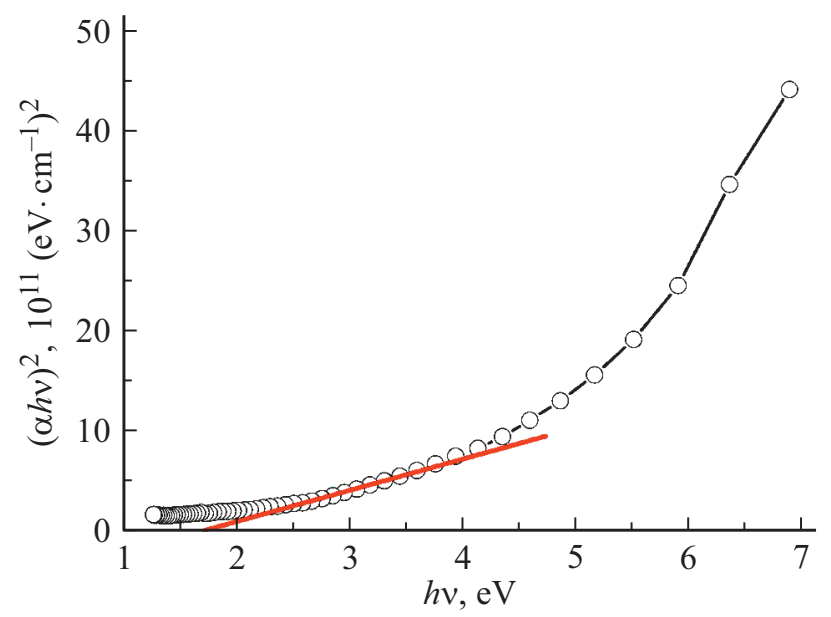

Рис. 5. Графическое определение оптической ширины запрещенной зоны $E_{g}$ тонкой пленки $\mathrm{SnSe}$, осажденной на матированное стекло из трилонатной системы, при прямых оптических переходах.

Дифракционные рефлексы с малыми кристаллографическими индексами $\mathrm{SnSe}$ на рентгенограмме отсутствуют в связи с небольшой толщиной слоя.

Кроме того, на рентгенограмме присутствует основной рефлекс, принадлежащий оксиду олова $\mathrm{SnO}_{2}$, при этом отметим, что не обозначенные на рис. 4, 2 рефлексы принадлежат подложке из ситалла. Наличие дифракционных отражений оксидной фазы на рентгенограмме селенида олова (II), полученного электроосаждением, обнаружено и авторами [38], однако никаких объяснений этому не было дано.

Проведенное уточнение параметров кристаллической решетки $\mathrm{SnSe}$ с использованием программного продукта FullProf показало значение $a=(11.481 \pm 0.005) \AA$, $b=(4.155 \pm 0.005) \AA, c=(4.437 \pm 0.005) \AA$, которые хорошо согласуются с литературными данными $[12,39,40]$.

Помимо основной фазы $\mathrm{SnSe}$ на рентгенограмме (рис. 4) можно наблюдать рефлекс при $2 \theta=42.76^{\circ}$, идентификация которого позволила отнести его к тетрагональной кристаллической фазе $\left(P 4_{2} / \mathrm{mnm}\right)$ [41,42] c параметрами элементарной ячейки $a=b=$ $=(4.736 \pm 0.002) \AA, c=(3.192 \pm 0.002) \AA[42-44]$.

Для определения оптической ширины запрещенной зоны осажденных пленок $\mathrm{SnSe}$ были сняты их спектры поглощения в диапазоне длин волн $220-2600$ нм с шагом 2 нм, математическая обработка которых выявила максимальное значение коэффициента поглощения $\alpha$, равное $9.5 \cdot 10^{4} \mathrm{~cm}^{-1}$ при $\lambda=285 \mathrm{Hм}$.

Расчет ширины запрещенной зоны проводился для случая прямых электронных переходов с использованием соотношения Бардина. Для этого была построена зависимость величины $(\alpha h v)^{2}$ от энергии падающих фотонов $h v$ (рис. 5). Экстраполяция линейного участка до пересечения с осью абсцисс позволила определить значение оптической ширины запрещенной зоны $E_{g}$ пленки $\mathrm{SnSe}$.

Из анализа спектра пропускания установлено, что химически осажденный тонкопленочный селенид олова имеет оптическую ширину запрещенной зоны для прямых переходов 1.69 эВ. Известно, что в случае объемного селенида олова (II) при комнатной температуре значение $E_{g}$ для прямых переходов, по данным [45], равно 1.30 эВ.

Отметим, что в полученных пленках $\mathrm{SnSe}$ наблюдается „голубое“ смещение, т.е. происходит сдвиг края полосы поглощения в сторону меньших длин волн по сравнению с монокристаллическим материалом на 0.39 эВ для прямых переходах. Возможными причинами этого эффекта могут быть, во-первых, меньший размер частиц, формирующих пленку $\mathrm{SnSe}$, вследствие чего возникают квантово-размерные эффекты, а во-вторых, присутствие примесных фаз. Поскольку синтезированные в настоящей работе слои селенида олова (II) сформированы из частиц, размер которых превышает пороговую величину $(\sim 10-15$ нм $[46])$, к изучаемым объектам невозможно применить размерный эффект в качестве обоснованного объяснения наблюдаемого изменения ширины запрещенной зоны. С другой стороны, по результатам рентгеновской фотоэлектронной спектроскопии и рентгенофазового анализа была идентифицирована оксидная фаза олова $\mathrm{SnO}_{2}$, которая за счет своей широкозонной природы $\left(E_{g}=3.57\right.$ эВ [44]) увеличивает значение ширины запрещенной зоны, сдвигая тем самым край поглощения в коротковолновую область спектра.

Значения оптической ширины запрещенной зоны для прямых межзонных переходов тонкопленочных слоев $\mathrm{SnSe}$, изучаемых в настоящей работе, согласуется с данными работ $[12,17,18,47]$, где представлены результаты исследования пленок селенида олова (II), полученных как химическим осаждением из водных сред, так и вакуумным испарением.

Свежеосажденные тонкопленочные слои селенида олова (II) обладают характерным для изучаемого полупроводникового соединения выраженным $p$-типом про- 
водимости, установленным методом термоэдс, что согласуется с данными публикаций $[39,40]$.

\section{4. Заключение}

Химическим осаждением из реакционной смеси, содержащей хлорид олова $\mathrm{SnCl}_{2}$, Трилон Б $\left(\mathrm{C}_{10} \mathrm{H}_{14} \mathrm{~N}_{2} \mathrm{Na}_{2} \mathrm{O}_{8}\right)$ и селеносульфат натрия $\mathrm{Na}_{2} \mathrm{SeSO}_{3}$, получены высокоадгезионные зеркальные пленки моноселенида олова толщиной до $(200 \pm 10)$ нм. Рентгеновской дифракцией установлено, что тонкопленочный $\mathrm{SnSe}$ кристаллизуется в орторомбической структуре (пр. гр. Рпта) с параметрами решетки $a=(11.481 \pm 0.005) \AA$, $b=(4.155 \pm 0.005) \AA, c=(4.437 \pm 0.005) \AA$. РФЭ-спектроскопией показано, что на поверхности тонкопленочного слоя произошло формирование фазы диоксида олова $\mathrm{SnO}_{2}$. По результатам ионного травления практически все олово на глубине 18 нм находится в двухвалентном состоянии в составе соединения SnSe. Найденное из спектра поглощения значение оптической ширины запрещенной зоны химически осажденной пленки $\mathrm{SnSe}$ для случая прямых электронных переходов составило 1.69 эВ. Некоторое превышение этого значения в сравнении с объемными образцами $\mathrm{SnSe}$ служит косвенным подтверждением частичного окисления олова (II) на поверхности пленки с образованием следовых количеств широкозонного $\mathrm{SnO}_{2}$. Синтезированные слои $\mathrm{SnSe}$ обладают характерным для этого полупроводникового соединения дырочным типом проводимости, установленным методом термоэдс.

Работа поддержана программой 211 правительства Российской Федерации № 02.А03.21.0006. Оптические измерения выполнены в рамках программы Министерства науки и высшего образования Российской Федерации АААА-А16-116122810218-7.

\section{Список литературы}

[1] N.R. Mathews. Sol. Energy, 86, 1010 (2012).

[2] V.R.M. Reddy, S. Gedi, B. Pejjai, C. Park. J. Mater. Sci.: Mater. Electron., 27 (6), 5491 (2016).

[3] Т.М. Разыков, К.М. Кучкаров, Б.А. Эргашев, Р.Т. Йулдошов, О.М. Турсункулов. Гелиотехника, 2, 3 (2017).

[4] G. Jeong, J. Kim, O. Gunawan, S.R. Pae, S.H. Kim, J.Y. Song, Y.S. Lee, B. Shin. J. Alloys Compd., 722, 474 (2017).

[5] A. Zakutayev. Curr. Opin. Green Sustainable Chem., 4, 8 (2017).

[6] L.C. Zhang. Sci. Rep., 6, 19830 (2016).

[7] В.С. Бойко, В.И. Гарбер, А.М. Косевич. Обратимая пластичность кристаллов (М., Наука, 1991).

[8] M. Wu, X.C. Zeng. Nano Lett., 16, 3236 (2016).

[9] Л.А. Чернозатонский, А.А. Артюх. УФН, 188 (1), 3 (2018).

[10] G. Jeong, J. Kim, O. Gunawan, S.R. Pae, S.H. Kim, J.Y. Song, Y.S. Lee, B. Shin. J. Alloys Compd., 722, 474 (2017).

[11] M.R. Burton, T.J. Liu, J. Mc Gettrick, S. Mehraban, J. Baker, A. Pockett, T. Watson, O. Fenwick, M.J. Carnie. Adv. Mater., 30 (31), 1801357 (2018).
[12] T.M. Razykova, G.S. Boltaev, A. Bosio, B. Ergashev, K.M. Kouchkarov, N.K. Mamarasulov, A.A. Mavlonov, A. Romeo, N. Romeo, O.M. Tursunkulov, R. Yuldoshov. Sol. Energy, 159, 834 (2018).

[13] K.S. Urmila, T.A. Namitha, J. Rajani, R.R. Philip, B. Pradeep. J. Semiconductors, 37 (9), 093002 (2016).

[14] В.Ф. Дьяков, В.Ф. Марков, Л.Н. Маскаева, М.П. Миронов, Н.А. Третьякова. Изв. вузов. Сер.: Химия и хим. технология, 51, 37 (2008).

[15] М.П. Миронов, Л.Д. Лошкарева, Л.Н. Маскаева, В.Ф. Марков. Бутлеровские сообщения, 19 (1), 25 (2010).

[16] E. Barrios-Salgado, M.T.S. Nair, P.K. Nair. ECS J. Solid State Sci. Technol., 3 (8), Q169 (2014).

[17] V.R. Solanki, R.J. Parmar, R.J. Pathak, M.D. Parmar. AIP Conf. Proc., 1837, 040019 (2017).

[18] P.K. Nair, A.K. Martínez, A.R.G. Angelmo, E.B. Salgado, M.T.S. Nair. Semicond. Sci. Technol., 33 (3), 035004 (2018).

[19] М.В. Кузнецов. Современные методы исследования поверхности твердых тел: ботоэлектронная спектроскопия и дибракция, СТМ-микроскопия (Екатеринбург, УpO РAH, 2010).

[20] А.М. Филачев, И.И. Таубкин, М.А. Тришенков. Твердотельная фотоэлектроника. Физические основы (М., Физматкнига, 2007).

[21] В.Ф. Марков, Л.Н. Маскаева. Изв.АН. Сер. хим., № 7, 1523 (2014).

[22] S. Badrinarayanan, A.B. Mandale, V.G. Gunjikar, A.P.B. Sinha. J. Mater. Sci., 21, 3333 (1986).

[23] S. Gubbala, H.B. Russell, H. Shah, B. Deb, J. Jasinski, H. Rypkemac, M.K. Sunkara. Energy Environ. Sci., 2, 1302 (2009).

[24] S. Wu, S. Yuan, L. Shi, Y. Zhao, J. Fang. J. Colloid Interface Sci., 346, 12 (2010).

[25] M. Kwoka, G. Czempik, J. Szuber. Acta Phys. Slovaca, 55, 331 (2005).

[26] Y.C. Her, J.Y. Wu, Y.R. Lin, S.Y. Tsai. Appl. Phys. Lett., 89, 043115 (2006).

[27] Э.П. Домашевская, С.В. Рябцев, С.Ю. Турищев, В.М. Кашкаров, Ю.А. Юраков, О.А. Чувенкова, А.В. Щукарев. Конденсированные среды и межфазные границы, 10 (2), 98 (2008).

[28] Q. Han, Y. Zhu, X. Wang, W. Ding. J. Mater. Sci., 39, 4643 (2004).

[29] N.D. Boscher, C.J. Carmalt, R.G. Palgrave, I.P. Parkin. Thin Sol. Films, 516, 4750 (2008).

[30] L.L. Ma, Z.D. Cui, Z.Y. Li, S.L. Zhu, Y.Q. Liang, Q.W. Yin, X.J. Yang. Mater. Sci. Eng. B, 178, 77 (2013).

[31] K. Ananthi, K. Thilakavathy, N. Muthukumarasamy, S. Dhanapandian, K.R. Murali. J. Mater. Sci.: Mater. Electron., 23, 1338 (2012).

[32] З.И. Смирнова, Л.Н. Маскаева, В.Ф. Марков, В.И. Воронин, М.В. Кузнецов. Конденсированные среды и межфазные границы, 14 (2), 250 (2012).

[33] О.А. Чувенкова, Э.П. Домашевская, С.В. Рябцев, Ю.А. Юраков, А.Е. Попов, Д.А. Коюда, Д.Н. Нестеров, Д.Е. Спирин, Р.Ю. Овсянников, С.Ю. Турищев. ФТТ, 57 (1), 145 (2015).

[34] R. Drevet, D. Dragoé, M.G. Barthés-Labrousse, A. Chaussé, M. Andrieux. Appl. Surf. Sci., 384, 442 (2016).

[35] В.Б. Спиваковский. Аналитическая химия олова (М., Наука, 1975).

[36] L.D. Zhao, S.H. Lo, Y. Zhang, H. Sun, G. Tan, C. Uher, C. Wolverton, V.P. Dravid, M.G. Kanatzidis. Nature, 508 (7496), 373 (2014). 
[37] C.W. Li, J. Hong, A.F. May, D. Bansal, S. Shi, T. Hong, G. Ehlers, O. Delaire. Nature Phys., 11 (12), 1063 (2015).

[38] B. Subramanian, T. Mahalingam, C. Sanjeeviraja, M. Jayachandran, M.J. Chockalingam. Thin Sol. Films, 357, 119 (1999).

[39] E. Barrios-Salgado, M.T.S. Nair, P.K. Nair. Thin Sol. Films, 598, 149 (2016).

[40] V. Kumar, P. Kumar, S. Yadav, V. Kumar, M.K. Bansal, D.K. Dwivedi. Mater. Sci.: Mater. Electron., 27, 4043 (2016).

[41] M. Thirumoorthi, J.T.J. Prakash. Superlat. Microstruct., 89, 378 (2016).

[42] A. Abdelkrima, S. Rahmane, O. Abdelouahab, N. Abdelmalek, G. Brahim. Optik, 127, 2653 (2016).

[43] Z.V. Borges, C.M. Poffo, J.C. de Lima, S.M. de Souza, D.M. Trichês, T.P.O. Nogueira, L. Manzato, R.S. de Biasi. Mater. Chem. Phys., 169, 47 (2016).

[44] A.A. Yadav, S.C. Pawar, D.H. Patil, M.D. Ghogare. J. Alloys Compd., 652, 145 (2015).

[45] B. Pejova, I. Grozdanov. Thin Sol. Films, 515, 5203 (2007).

[46] А.И. Гусев. Нанокристаллические материалы: методы получения и свойства (Екатеринбург, УрО РАН, 1998).

[47] N. Kumar, U. Parihar, R. Kumar, K.J. Patel, C.J. Panchal, N. Padha. Amer. J. Mater. Sci., 2, 41 (2012).

Редактор Л.В. Шаронова

Composition, structure, semiconductor properties

\section{of chemically deposited SnSe films}

L.N. Maskaeva ${ }^{1,2}$, E.A. Fedorova ${ }^{1}$, V.F. Markov ${ }^{\mathbf{1 , 2}}$, M.V. Kuznetsov ${ }^{3}$, O.A. Lipina ${ }^{3}$

${ }^{1}$ Ural Federal University named after

the first President of Russia B.N. Yeltsin,

620002 Yekaterinburg, Russia

${ }^{2}$ Ural Institute of State Fire Service

of EMERCOM of Russia,

620022 Yekaterinburg, Russia

${ }^{3}$ Institute of Solid State Chemistry,

Ural Branch of Russian Academy of Sciences,

620990 Yekaterinburg, Russia

Abstract High adhesion tin monoselenide SnSe layers with the thickness of up to $(200 \pm 10) \mathrm{nm}$ have been prepared by hydrochemical deposition from a trilonate reaction mixture. It was revealed by the $X$-ray diffraction method that the synthesized films crystallized in the orthorhombic system (space group Pnma). The presence of a significant amount of oxygen in the surface layers of the films is explained by partial oxidation of the samples with formation of the $\mathrm{SnO}_{2}$ phase. The results of ion etching to the depth of $18 \mathrm{~nm}$ showed a sharp decrease in the oxygen content with depth and actual correspondence of the elemental composition to SnSe. According to the results of optical studies, the band gap was found to be $1.69 \mathrm{eV}$ for direct type of transitions. The synthesized SnSe layers have a hole-type conductivity typical of this material. 